Sitzungsberichte

der Akademie der Wissenschaften der DDR

Mathematik - Naturwissenschaften - Technik

Günter Pasternak

\title{
Immunsystem und \\ Krebserkrankung
}


